\title{
A cross sectional evaluation of attitude and knowledge of Indian nursing students towards electroconvulsive therapy
}

\author{
Yatan Pal Singh Balhara ${ }^{1}$, Shachi Mathur ${ }^{2}$ \\ ${ }^{1}$ Department of Psychiatry and De-addiction, Lady Hardinge Medical College and SSK Hospital, ${ }^{2}$ Jamia Milia \\ Islamia, New Delhi, India.
}

\section{ARTICLE INFO}

Received

$: 22 / 03 / 2012$

Accepted : :27/05/2012

Published : :01/12/2012

\section{KEYWORD}

Nursing education

Nursing specialty

Electroconvulsive therapy

Attitude

Knowledge

\section{ABSTRACT}

Objective: Studies from American and European countries have explored the attitudes and knowledge of nurses and nursing students towards electroconvulsive therapy (ECT). However, there is a limited literature on the attitude and knowledge of nursing students towards ECT from Asian and African countries. The current study aims at assessing the knowledge and attitude of Indian nursing students towards ECT. Method: The study was conducted at a nursing college attached to a tertiary care multi-specialty hospital. Knowledge and attitude of the nursing students were assessed using the questionnaire developed by Kinnair and Dawson. We included students from third year and final year of nursing training. Data analysis was carried out using SPSS version 17.0. Level of statistical significance was kept at $p<0.05$ for all the tests. Result: A total of 47 nursing students (25 third year and 22 final year) were approached for participation in the study. Final year nursing students had a significantly higher score on the indication and procedure domains of the ECT knowledge questionnaire. Third year students had a significantly higher score on the adverse effect domain of the questionnaire. Conclusion: Te findings of the current study highlight the need for modifications to the existing nursing training curriculum. There is need to address the issues related mental health including interventions for mental disorders. These changes would help improve the knowledge as well as attitude of nursing students towards ECT.

(C) Medical Education Department, School of Medical Sciences, Universiti Sains Malaysia. All rights reserved.

CORRESPONDING AUTHOR: Dr Yatan Pal Singh Balhara, MBBS, MD, DNB (Psychiatry), MNAMS, Assistant Professor Department of Psychiatry and De-addiction Lady Hardinge Medical College and SSK Hospital, New Delhi, India.

Tel: +91 9868976365, Email: ypsbalhara@gmail.com 


\section{Introduction}

Electroconvulsive therapy (ECT) is one of the most effective psychiatric interventions available today. Its use has been recommended, in combination with antipsychotics, for rapid reduction of symptoms in patients with schizophrenia (1). ECT has been found to be more effective than pharmacotherapy for depression in the short. There is some evidence to suggest that it is more effective than (repetitive Transcranial Magnetic Stimulation) rTMS for this condition (2). Its effectiveness has also been documented in mania as well $(3,4)$.

There are no absolute contraindications to use of ECT. Over the years, modifications in techniques of administration of ECT have reduced the complications associated with its use. It is a relatively safe medical procedure with a reported mortality rate of 2 to 4.5 per 100,000 procedures carried out (5). This rate is comparable to the risk associated to short-term anaesthesia in small surgical procedures.

In spite of the efficacy and relative safety of the procedure, concerns have been expressed about acceptance of this therapeutic modality by various stakeholders. These debates have cantered on the safety and ethical issues (6). The available evidence on attitudes of health professionals reflects mixed findings. While many studies support a favourable attitude among mental health professionals, this is not a uniform observation (7). Studies have reported unfavourable attitudes towards ECT among mental health professionals well (8-10).

Studies from American and European countries have explored the attitudes and knowledge of nurses and nursing students towards ECT (1113).

However, there is a limited literature on the attitude and knowledge of nursing students towards ECT from Asian and African countries. It is important to study attitude of future nurses towards ECT. Nurses, among all health care professionals, spend the most time with the patients. Their attitudes are likely to influence their patients' attitudes (11). The current study aims at assessing the knowledge and attitude of Indian nursing students towards ECT. Additionally, the study aims at comparing the knowledge and attitude of the third and final year nursing students.

\section{Method}

The study was conducted at a nursing college attached to a tertiary care multi-specialty hospital. The nursing college runs undergraduate programme in nursing education. Nursing students in the third year and final year of training constituted study constituted the sampling frame. All students consenting to participate in the study were considered eligible. The students were explained about the study. Those willing to participate and consenting for the same were included in the study. Those refusing to participate were excluded from the study. The students were administered the study questionnaire.

\section{Study questionnaire}

We used the questionnaire developed by Kinnair and Dawson (14). A written permission was obtained from the authors to use the questionnaire. The study questionnaire aimed at assessment of knowledge as well as attitudes of students towards ECT. The first part of the questionnaire consisted of a total of 21 items aimed at assessing the knowledge of the students about indications (6 items), procedure (10 items) and adverse effects (5 items) of ECT. The students were expected to mark the items as true or false. The final score was calculated by summing up the number of correct responses in each of the three domains separately. Each correct response is scored as 1 and incorrect response is scored 0 . The scores on indications, procedure and adverse effects were calculated by adding the correct responses to the items for the respective domains.

The second part of the questionnaire comprised of thirteen items aimed at assessment of attitudes of students towards ECT. The students were expected to mark their responses as 'agree' or 
'disagree' to the individual items. Identity of study participant was kept confidential and the ethical principals outlined in the ethical guidelines were adhered to during the course of the study.

\section{Statistical analysis}

Data analysis was carried out using SPSS version 17.0. Descriptive statistics were used for the socio-demographic profile of the study subjects. In between group comparisons for the third year and final year nursing students was carried out using the independent sample $t$ test and chi square test. Level of statistical significance was kept at $p<0.05$ for all the tests.

\section{Result}

A total of 47 nursing students (25 third year and 22 final year) were approached for participation in the study. All the students agreed for participation and returned the completed study questionnaire. All the study subjects were females. The mean age of the third year (20.56 $S D \pm .58$ years) and final year (21.22 $S D \pm 0.52$ years) students in the two groups was comparable $(t=-4.08, p=0.12)$.

The two groups were comparable with regards to 'ever witnessed administration of ECT' (chi square $=.41, d f=1, p=0.52$ ) and 'ever attended a lecture about ECT' (chi square $=1.91, d f=1$, $p=0.16$ ). The mean scores for third year and final year students on indication, procedure and adverse effect domains of the ECT knowledge questionnaire have been presented in table 1 . Final year nursing students had a significantly higher score on the indication $(t=-1.97, p=0.02)$ and procedure $(t=-1.73, p=0.04)$ domains of the ECT knowledge questionnaire. Third year students had a significantly higher score on the adverse effect domain of the questionnaire ( $t=$ $.92, p=.01)$.The two groups were comparable on most items of the attitude towards ECT questionnaire (table 2). A significantly higher proportion of third year students disagreed to the statement 'ECT is barbaric' (chi square $=10.66$, $d f=1, p=0.001)$. A significantly greater proportion of final year students agreed with the statements 'I would feel comfortable watching ECT being administered' (chi square $=5.92, \mathrm{df}=$ $1, \mathrm{p}=0.01$ ) and 'I would feel comfortable administering ECT (if I had received the correct training)' $($ chi square $=5.64, \mathrm{df}=1,=0.01$ ).

\section{Discussion}

The current study aimed at assessment of knowledge and attitude of Indian nursing students towards Electro Convulsive Therapy. A comparative evaluation was performed between the third year and final year nursing students. Final year nursing students had a significantly higher knowledge about the indications and procedure of ECT. On the other hand, third year students had a significantly greater knowledge about the adverse effect of ECT. The two groups differed only on three of the thirteen attitudes related statements. Studies from American and European countries have explored the attitudes of nurses towards ECT (11-13, 15-17). However the information is limited about the attitude of nursing students towards this important psychiatric intervention.

There is no information about attitude and knowledge of nursing students from Asian countries. Nurses have been found to have a lesser knowledge about ECT than physicians (12). A comparative study among Irish medical and nursing professionals found relatively poorer knowledge of ECT in the nursing group (including psychiatric nurses). Around one third of the nurses overestimated ECT mortality and most did not know if it caused permanent brain damage. Only one psychiatric nurse expressed positive attitudes to its use. In this study nursing students had significantly lower knowledge and more negative attitudes than medical students. Moreover, no significant associations were observed between the knowledge and attitudes of nursing students (15). A study from London reported relatively poorer knowledge of ECT among nurses as compared to psychiatrists. Although their knowledge was greater than social workers and psychologists (17).

A Nigerian study comparing knowledge and attitude of student nurses and staff mental health 
nurses showed that knowledge and attitude scores were more positive among staff mental health nurses compared with student mental health (18). In another study nurses were more likely to consider ECT helpful than general public but less than psychiatrists (16).

ECT has been found to be an effective and relatively safe intervention in psychiatry. In spite of the available evidence, ECT continues to be classified as Class III (high risk) by the Neurological Devices Panel, a federal advisory body to the Food and Drug Administration (FDA), for all indications for use with the exception of catatonia (19). It is important to study the attitude and knowledge of the health professionals involved in administration of this therapy.

Better knowledge about ECT related facts has been found to be associated with positive attitudes towards the procedure $(13,20)$. Lack of prior exposure to ECT has been cited an important reason for less favourable attitudes towards ECT. Of all the health professionals, nurses spend the maximum time with the patients. Role of nurses in providing detailed and accurate information about ECT to patients has been recognized (21). Nurses are involved in providing emotional and educational support to patient and care givers; pre-treatment assessment; and observing patients' response to the procedure (22). Nurses' knowledge and attitudes is conveyed to patients during the clinical care $(11,12)$. Hence knowledge and attitude of nurses towards ECT is likely to influence treatment choice. Nursing students, as future nurses, would be involved in consent taking procedure of the patients requiring ECT. Inadequate knowledge and unfavourable attitudes are likely to impact their approach to this process. Interestingly some reports have suggested comparatively less favourable attitudes towards ECT among nurses working in education (16).

Need for specialized training of the health professionals involved in ECT administration has been recommended earlier (13, 23). Training program aimed at giving nurses knowledge and practical skills in key components of ECT has been shown to improve the knowledge and attitude of nurses towards ECT (20). Additionally, greater experience of nurses has also been found to be associated with greater knowledge and positive attitude towards ECT (12). In the current study the attitudes of nursing students were comparable across the tow training years. There was a little change in attitude with increase in training. Similarly the knowledge about ECT did not increase consistently with increase in professional training.

Te findings of the current study highlight the need for modifications to the existing nursing training curriculum. There is need to address the issues related mental health including interventions for mental disorders. These changes would help improve the knowledge as well as attitude of nursing students towards ECT. The current study has certain limitations. We assessed students from a single nursing college. The findings need to be replicated in other settings before they could be generalized. Also we made cross sectional assessments. It would be interesting to follow these students in future and assess their knowledge and attitudes once they start clinical care delivery. Additionally, only female students were included due to logistic reasons. Future studies should include male students as well for such evaluations.

\section{Reference}

1. Tharyan P, Adams CE. Electroconvulsive therapy for schizophrenia. Cochrane Database Syst Rev. 2005(2):CD000076.

2. Efficacy and safety of electroconvulsive therapy in depressive disorders: a systematic review and meta-analysis. Lancet. 2003;361(9360):799-808.

3. Sikdar S, Kulhara P, Avasthi A, Singh H. Combined chlorpromazine and electroconvulsive therapy in mania. $\mathrm{Br} \mathrm{J}$ Psychiatry. 1994;164(6):806-10.

4. American Psychiatric Association. The practice of electroconvulsive therapy: recommendations for treatment, training and privileging. Washington, DC: American Psychiatric Association Press, 2001.

5. Babigian HM, Guttmacher LB. Epidemiologic considerations in 
electroconvulsive therapy. Arch Gen Psychiatry. 1984;41(3):246-53.

6. Reisner AD. The electroconvulsive therapy controversy: evidence and ethics. Neuropsychol Rev. 2003;13(4):199-219.

7. Payne NA, Prudic J. Electroconvulsive therapy: Part II: a biopsychosocial perspective. J Psychiatr Pract. 2009;15(5):369-90.

8. Breggin P. Toxic psychiatry: Why therapy, empathy and love must replace the drugs, electroshock, and biochemical theories of the 'New Psychiatry.'. New York: St. Martin's Press; 1991.

9. Kalayam B, Steinhart M. A survey of attitudes on the use of electroconvulsive therapy. Hosp Community Psychiatry. 1981;32:185-7.

10. Lutchman R, Stevens T, Bashir A. Mental health professionals' attitudes towards and knowledge of electroconvulsive therapy. J Ment Health. 2001;10(141-150).

11. Wood JH, Chambers M, White SJ. Nurses' knowledge of and attitude to electroconvulsive therapy. J ECT. 2007;23(4):251-4.

12. Janicak PG, Mask J, Trimakas KA, Gibbons R. ECT: an assessment of mental health professionals' knowledge and attitudes. J Clin Psychiatry. 1985;46(7):262-6.

13. Gass JP. The knowledge and attitudes of mental health nurses to electro-convulsive therapy. J Adv Nurs. 1998;27(1):83-90.

14. Kinnair D, Dawson S. Electroconvulsive therapy: medical students' attitudes and knowledge. The Psychiatrist. 2010;34:54-7.

15. Byrne P, Cassidy B, Higgins P. Knowledge and attitudes toward electroconvulsive therapy among health care professionals and students. J ECT. 2006;22(2):133-8.

16. Caldwell TM, Jorm AF. Mental health nurses' beliefs about interventions for schizophrenia and depression: a comparison with psychiatrists and the public. Aust N Z J Psychiatry. 2000;34(4):602-11.

17. Lutchman R, Stevens T, Bashir A. Mental health professionals' attitudes towards and knowledge of electroconvulsive therapy. J Ment Health. 2001;110(2):141-50.

18. James BO, Lawani AO, Omoaregba JO, Isa EW. Electroconvulsive therapy: a comparison of knowledge and attitudes of student nurses and staff mental health nurses at a psychiatric hospital in Nigeria. J Psychiatr Ment Health Nurs. 2010;17(2):141-6.
19. Rosedale M. Our patients' lives are worth fighting for and electroconvulsive therapy (ECT) saves lives: a compendium of the evidence. J Am Psychiatr Nurses Assoc. 2011;17(3):209-11.

20. Munday J, Deans C, Little J. Effectiveness of a training program for ECT nurses. $\mathrm{J}$ Psychosoc Nurs Ment Health Serv. 2003;41(11):20-6.

21. Branfield M. ECT for depression in elderly people. Nurs Stand. 1992;6(26):24-7.

22. Burns CM, Stuart GW. Nursing care in electroconvulsive therapy. Psychiatr Clin North Am. 1991;14(4):971-88.

23. Pippard J. Audit of electroconvulsive treatment in two national health service regions. Br J Psychiatry. 1992;160:621-37. 
Table 1: In between group differences for third year and final year nursing students for age and knowledge about ECT

\begin{tabular}{|c|c|c|c|c|c|c|c|}
\hline \multirow{2}{*}{ Variable } & \multirow{2}{*}{$\begin{array}{l}\text { Year of } \\
\text { training }\end{array}$} & \multirow{2}{*}{ Mean } & \multirow{2}{*}{$\begin{array}{l}\text { Std. } \\
\text { Deviation }\end{array}$} & \multirow{2}{*}{ t value } & \multirow{2}{*}{$p$ value } & \multicolumn{2}{|c|}{ 95\% Confidence Interval } \\
\hline & & & & & & Lower & Upper \\
\hline \multirow[t]{2}{*}{ Age (in years) } & Third & 20.56 & .58 & \multirow{2}{*}{-4.08} & \multirow{2}{*}{.12} & \multirow{2}{*}{-.99} & \multirow{2}{*}{-.33} \\
\hline & Final & 21.22 & .52 & & & & \\
\hline \multirow[t]{2}{*}{ ECT Indication } & Third & 4.72 & 1.27 & \multirow{2}{*}{-1.97} & \multirow{2}{*}{.02} & \multirow{2}{*}{-1.30} & \multirow{2}{*}{.01} \\
\hline & Final & 5.36 & .90 & & & & \\
\hline \multirow[t]{2}{*}{ ECT procedure } & Third & 6.12 & 1.73 & \multirow{2}{*}{-1.73} & \multirow{2}{*}{.04} & \multirow{2}{*}{-1.70} & \multirow{2}{*}{.12} \\
\hline & Final & 6.90 & 1.30 & & & & \\
\hline \multirow[t]{2}{*}{ ECT adverse effects } & Third & 3.16 & 1.06 & \multirow{2}{*}{.92} & \multirow{2}{*}{.01} & \multirow{2}{*}{-.40} & \multirow{2}{*}{1.08} \\
\hline & Final & 2.81 & 1.46 & & & & \\
\hline
\end{tabular}

Table 2: In between group differences for third year and final year nursing students for attitude towards ECT

\begin{tabular}{|c|c|c|c|c|}
\hline Item & Response & $\begin{array}{l}\text { Third year } \\
\text { (percentage) }\end{array}$ & $\begin{array}{l}\text { Final year } \\
\text { (percentage) }\end{array}$ & Chi square, $p$ value \\
\hline \multirow[t]{2}{*}{ ECT is barbaric } & Disagree & 96.0 & 53.3 & \multirow{2}{*}{$10.66, \mathrm{df}=1, p=.001$} \\
\hline & Agree & 4.0 & 46.7 & \\
\hline \multirow[t]{2}{*}{ ECT is outmoded and should never be used } & Disagree & 100 & 100.0 & \multirow{2}{*}{ NA } \\
\hline & Agree & 0 & 0 & \\
\hline \multirow[t]{2}{*}{ There is no evidence that ECT is effective } & Disagree & 100 & 100.0 & \multirow{2}{*}{ NA } \\
\hline & Agree & 0 & 0 & \\
\hline \multirow[t]{2}{*}{ ECT can be life saving for some patients } & Disagree & 27.8 & 18.2 & \multirow{2}{*}{$0.52, \mathrm{df}=1, p=.47$} \\
\hline & Agree & 72.2 & 81.8 & \\
\hline \multirow{2}{*}{$\begin{array}{l}\text { ECT can get patients better more quickly than } \\
\text { antidepressants }\end{array}$} & Disagree & 23.1 & 14.3 & \multirow{2}{*}{$0.42, \mathrm{df}=1, p=.51$} \\
\hline & Agree & 76.9 & 85.7 & \\
\hline \multirow{2}{*}{$\begin{array}{l}\text { ECT should only be used in serious or life- } \\
\text { threatening situations }\end{array}$} & Disagree & 52.9 & 22.7 & \multirow{2}{*}{$3.80, \mathrm{df}=1, p=.06$} \\
\hline & Agree & 47.1 & 77.3 & \\
\hline \multirow[t]{2}{*}{ Patients feel coerced into having ECT } & Disagree & 76.2 & 47.4 & \multirow{2}{*}{$3.53, \mathrm{df}=1, p=.06$} \\
\hline & Agree & 23.8 & 52.6 & \\
\hline \multirow[t]{2}{*}{ Some patients agree to have ECT } & Disagree & 27.3 & 23.8 & \multirow{2}{*}{$0.06, \mathrm{df}=1, p=.79$} \\
\hline & Agree & 72.7 & 76.2 & \\
\hline \multirow{2}{*}{$\begin{array}{l}\text { ECT should only be given under the Mental Health } \\
\text { Act }\end{array}$} & Disagree & 26.3 & 27.3 & \multirow{2}{*}{$0.005, \mathrm{df}=1, p=.94$} \\
\hline & Agree & 73.7 & 72.7 & \\
\hline \multirow[t]{2}{*}{ I would agree to have ECT if I were depressed } & Disagree & 50.0 & 71.4 & \multirow{2}{*}{$2.14, \mathrm{df}=1, p=.14$} \\
\hline & Agree & 50.0 & 28.6 & \\
\hline \multirow[t]{2}{*}{ I would recommend ECT to my patients } & Disagree & 29.2 & 23.8 & \multirow{2}{*}{$0.16, \mathrm{df}=1, p=.68$} \\
\hline & Agree & 70.8 & 76.2 & \\
\hline \multirow{2}{*}{$\begin{array}{l}\text { I would feel comfortable watching ECT being } \\
\text { administered }\end{array}$} & Disagree & 23.8 & 0 & \multirow{2}{*}{$5.92, \mathrm{df}=1, p=.01$} \\
\hline & Agree & 76.2 & 100.0 & \\
\hline \multirow{2}{*}{$\begin{array}{l}\text { I would feel comfortable administering ECT (if I } \\
\text { had received the correct training) }\end{array}$} & Disagree & 22.7 & 0 & \multirow{2}{*}{$5.64, \mathrm{df}=1, p=.01$} \\
\hline & Agree & 77.3 & 100.0 & \\
\hline
\end{tabular}

NA- chi square test not applicable 